\title{
EFEITO DE DOSES E ÉPOCAS DE APLICAÇÃO DE NITROGÊNIO NA INCIDÊNCIA DE DOENÇAS, PRODUÇÃO E QUALIDADE SANITÁRIA DAS SEMENTES DE ARROZ
}

\author{
Time and rate of nitrogen application on grain yield disease, and seed sanitary quality of rice
}

\author{
Vanda Maria de Oliveira Cornélio', Moizés de Souza Reis ${ }^{2}$, Antônio Alves Soares ${ }^{3}$, \\ Plínio César Soares ${ }^{4}$, João Almir Oliveira ${ }^{5}$
}

\begin{abstract}
RESUMO
Foram estudados os efeitos de doses e épocas de aplicação de Nitrogênio em arroz de terras altas no sistema de plantio direto sobre a ocorrência de brusone no campo, produção e qualidade sanitária das sementes. O trabalho foi conduzido no ano agrícola de 2001/2002 na fazenda experimental da EPAMIG em Lavras-MG (FELA/CTSM). Pelos resultados obtidos pode-se observar que para a brusone da folha e do fungo Dreschslera oryzae nas sementes houve efeito significativo da interação entre as doses e as épocas de aplicação do N. A brusone do pescoço da panícula foi influenciada pelo parcelamento das aplicações de $\mathrm{N}$, a maior dose de $\mathrm{N}$ aplicada na diferenciação do primórdio floral provocou maior severidade da doença. As doses crescentes de $\mathrm{N}$ favoreceram a incidência de $P$. grisea nas sementes e também a produtividade. Para o arroz de terras altas, em caso de parcelamento, deve-se concentrar a maior quantidade de $\mathrm{N}$ próximo a diferenciação do primórdio floral, onde o aproveitamento desse elemento é mais eficiente.
\end{abstract}

Termos para indexação: Oryza sativa, terras altas, plantio direto, adubação nitrogenada, brusone.

\section{ABSTRACT}

Time and rate of nitrogen application on upland rice were studied under no-till systems upon field blast (Pyricularia grisea) occurrence, grain yield and seed sanitary quality. The study was conducted in 2001/2002 at Agriculture and Livestock Research Institute (EPAMIG) Experiment Station at Lavras - MG, Brazil. There were significant interactions of leaf blast and Dreschslera oryzae fungi with rate and time of the nitrogen application. Split application of nitrogen affected the panicle neck blast, and the higher the rate of nitrogen applied on primary flower differentiation the greater disease severity. Increased $\mathrm{N}$ rates favored seed $P$.grisea incidence and rice yield. By splitining nitrogen application on upland rice, higher rates should be concentrate next to primary flower differentiation, when the use of this element is more efficient.

Index terms: Upland rice, no-till, nitrogen, blast, and seed quality.

\section{(Recebido para publicação em 10 de janeiro de 2005 e aprovado em 17 de agosto 2005)}

\section{INTRODUÇÃO}

A disponibilidade de nutrientes no solo pode ser considerada como um dos fatores responsáveis pela prédisposição de plantas ao ataque de patógenos. Segundo Krugner (1978), as quantidades de um determinado nutriente disponível no solo pode determinar maior ou menor resistência das plantas às doenças. $\mathrm{O}$ conhecimento dos efeitos da nutrição mineral sobre a suscetibilidade do hospedeiro a uma doença é muito importante, pois a nutrição desse hospedeiro está ligada às práticas de adubação.

Certos patógenos atacam severamente plantas subnutridas, enquanto que outros preferem plantas vigorosas. De modo geral, teores elevados de nitrogênio tendem a aumentar a suscetibilidade, enquanto que altas doses de potássio reduzem a predisposição a muitas doenças (KRUGNER, 1978).
Huber (1980) relaciona uma série de fatores que influenciam na relação do nitrogênio com a severidade de doenças: $\mathrm{pH}$, teor de água e outros elementos no solo, temperatura, preferência da cultura, microflora do solo e época de aplicação.

As pesquisas sobre efeito do nitrogênio em doenças de arroz de terras altas apontam para um aumento da severidade da maioria das doenças com doses crescentes do nutriente.

Ou (1987) e Zambolim \& Ventura (1993) relatam que o nitrogênio na forma nítrica é responsável pela redução da infecção provocada por Pyricularia grisea, fungo causador da brusone, e o nitrogênio amoniacal apresenta efeito inverso, aumentando os danos provocados por $P$. grisea. Entretanto, Webster \& Gunell (1992) relatam que a suscetibilidade da planta é maior quando o nitrogênio é aplicado na forma de nitrato $\left(\mathrm{NO}_{3}\right)$ que na forma amoniacal $\left(\mathrm{NH}_{4}\right)$.

${ }^{1}$ Pesquisadora da EPAMIG - Cx. P. 176 - 37.200-000 - Lavras, MG - vanda.cornelio@epamig.ufla.br

2Pesquisador da EPAMIG - Cx. P. 176 - 37.200-000 - Lavras, MG - moireis@ hotmail.com

${ }^{3}$ Professor do Departamento de Agricultura da Universidade Federal de Lavras/UFLA -Cx. P. 3037 - 37.200-000 - Lavras, MG - aasoares@ufla.br

${ }^{4}$ Pesquisador da EPAMIG/CTZM - Cx. P 216 - 36.570-000 - Viçosa, MG - plinio@epamig.ufv.br

${ }^{5}$ Professor do Departamento de Agricultura da Universidade Federal de Lavras/UFLA - Cx. P. 3037 - 37.200-000 - Lavras, MG - jalmir@ufla.br 
Experimentos conduzidos pelo Internacional Rice Research Institute e confirmados por Ou (1987) mostraram que aplicação de nitrogênio em arroz, concentrada no plantio ou 45 dias após, promove um aumento dos sintomas de brusone na folha e no pescoço da panícula.

Santos et al. (1986) também verificaram que doses elevadas de nitrogênio intensificam a severidade da brusone. Afirmam ainda que aplicação de todo o nitrogênio no sulco, por ocasião da semeadura, aumenta a severidade da brusone quando comparada com a aplicação parcelada. Entretanto, em outras pesquisas foi observado que a aplicação de todo $\mathrm{N}$ na semeadura resultou em menor severidade da brusone, comparativamente com as aplicações parceladas na semeadura e em cobertura.

Segundo Fernandes (1997), o desenvolvimento da agricultura tem motivado o homem a modificar, em maior ou menor grau, alguns aspectos do ecossistema em seu próprio benefício. Em algumas situações, as modificações têm alcançado tamanha magnitude que chega a caracterizar um subsistema diferenciado dos naturais e também dos culturais. O sistema de plantio direto (PD) é um dessas situações em que mudanças são muito significativas, diferenciando-o dos demais métodos culturais.

O plantio direto é considerado uma das práticas agrícolas mais eficientes no controle da erosão dos solos (PHILLIPS, 1993). Para Fernandes (1997), a palha deixada sobre a superfície do solo altera o microclima e influencia diretamente os processos biológicos que ocorrem neste ambiente.

A recomendação do PD no cultivo de arroz de terras altas encontra-se em fase de pesquisas e não se tem ainda resultados conclusivos acerca do benefício que o mesmo possa proporcionar. A maior limitação do arroz de terras altas ao PD talvez seja devido à redução na macroporosidade que o sistema provoca, que aliado à concentração superficial dos nutrientes, impedem o desenvolvimento radicular em profundidade, limitando a produtividade do arroz sobretudo em sistema e regiões dependentes de chuva (REIS et al., 2004).

Além dos problemas diretamente associados à deficiência hídrica, como esterilidade e o enchimento imperfeito das espiguetas, têm-se aqueles indiretamente associados, como a maior ocorrência de doenças, pela debilitação da planta que não consegue absorver nutrientes eficientemente e tem seus tecidos lesados pela limitada disponibilidade de água que ocorre nestas condições (GUIMARÃES \& YOKOYAMA, 1998).

Como o cultivo do arroz de terras altas em condições de plantio direto é relativamente novo e a adubação nitrogenada tem influência na severidade das doenças que ocorrem na cultura, com o trabalho, buscou-se estudar o efeito de doses e época de aplicação de nitrogênio na incidência de brusone no campo, produção e qualidade sanitária das sementes de arroz, cultivadas no sistema de PD, em condições de terras altas.

\section{MATERIAL E MÉTODOS}

O experimento de campo foi instalado no ano agrícola de 2001/02 na Fazenda Experimental da Epamig de Lavras (FELA), em condições de terras altas sob plantio direto. Utilizou-se delineamento de blocos casualizados em esquema fatorial $5 \times 3$ com três repetições, parcelas de cinco linhas com $5 \mathrm{~m}$ de comprimento, espaçadas de $0,40 \mathrm{~m}$ entre si. A adubação de plantio foi feita com $90 \mathrm{~kg} \mathrm{há}^{-1} \mathrm{de}$ $\mathrm{P}_{2} \mathrm{O}_{5}$ e $48 \mathrm{~kg}$ há-1 de $\mathrm{K}_{2} \mathrm{O}$. O nitrogênio foi aplicado na forma amoniacal e foram utilizados 15 tratamentos de manejo do nitrogênio, resultante da combinação de cinco doses de $\mathrm{N}$ : zero, 40, 80,120 e $160 \mathrm{~kg} / \mathrm{ha}$ de $\mathrm{N}$ com três épocas de aplicação: todo nitrogênio na semeadura; $1 / 2$ na semeadura e $1 / 2$ na diferenciação do primórdio floral ( DPF ) e $1 / 3$ na semeadura e o restante na DPF. A cultivar utilizada foi a Primavera, que apresenta ciclo semiprecoce, suscetibilidade ao acamamento e a brusone.

No campo foram feitas as avaliações de brusone nas folhas e brusone no pescoço da panícula. As observações foram visuais em toda área útil das parcelas, adotando-se a escala de notas de 1 à 9 proposta pela Embrapa (1977). Para a brusone das folhas, as observações foram realizadas nos estágios de perfilhamento e emergência da panícula, com base na área foliar atacada. A avaliação da brusone no pescoço da panícula também foi realizada pelo exame visual das parcelas, na fase de maturação das plantas.

A produção de grãos foi determinada pesando-se os grãos da área útil de cada parcela, após secagem, abanação e correção da umidade para $13 \%$.

A qualidade sanitária das sementes colhidas do ensaio foi analisada no laboratório de Patologia de Sementes da UFLA, segundo metodologia descrita por Neergaard (1977). Utilizou-se o método de papel de filtro analisando-se 400 sementes sem assepsia superficial por tratamento, em que avaliou-se os fungos Pyricularia grisea, Drechslera oryzae, Phoma sorghina e Gerlachia oryzae.

Os dados foram analisados pelo estudo de regressão e pelo teste de Tukey a 5\% de probabilidade, utilizando-se o pacote computacional SISVAR. Os dados de porcentagem foram transformados para: $\operatorname{arcsen} \sqrt{(\mathrm{x} / 100)}$, enquanto os 
dados provenientes de notas foram transformados $\operatorname{para} \sqrt{(\mathrm{x}+0,5)}$.

\section{RESULTADOS E DISCUSSÃO}

Procedeu-se inicialmente a análise de variância, em que se detectou interação significativa entre os fatores doses e épocas de aplicação do nitrogênio para as variáveis brusone nas folhas e incidência de Drechslera oryzae nas sementes. Para incidência de Pyricularia grisea nas sementes obteve-se efeito significativo para doses de nitrogênio, e para brusone na panícula e produtividade o efeito dos dois fatores foram significativos. As demais variáveis analisadas não apresentaram efeito significativo para nenhuma das fontes de variação.

Pelos resultados da avaliação de brusone nas folhas (Figura 1), observa-se que quando o $\mathrm{N}$ foi todo aplicado no plantio ocorreram as menores notas para severidade de brusone na folha, a exceção da dose zero. Com todo o $\mathrm{N}$ no plantio ocorre maior nitrificação precocemente e nitrato é pouco aproveitado pelo arroz na fase vegetativa. Isso indica menos disponibilidade de $\mathrm{N}$ para o arroz e, por conseguinte, menor ocorrência de brusone na folha. Esse resultado corrobora afirmação de Huber (1980) de que a época de aplicação de N influencia na relação desse nutriente com a severidade da doença. Nesse caso, dose de $\mathrm{N}$ influencia pouco na sua disponibilidade, uma vez que a nitrificação do $\mathrm{N}$ amoniacal é rápida e o N é pouco aproveitado pela planta. Quando as doses de $\mathrm{N}$ foram aplicadas parceladas no plantio e na diferenciação do primórdio floral (DPF), a severidade da doença aumentou com o incremento das doses de N. Estes resultados coincidem com os observados por Reis et al. (2004) e diferem dos encontrados por Santos et al. (1986). Deve-se ressaltar, no entanto, que esses dois autores não trabalharam em condições de plantio direto. Em trabalho realizado por Silva \& Prabhu (2004), em que se estudou o progresso da brusone nas folhas em plantio direto e convencional, verificou-se uma relação linear e significativa entre o conteúdo de clorofila e a severidade da brusone nas folhas, sugerindo haver efeito positivo do $\mathrm{N}$ sobre a severidade de brusone.

Para brusone do pescoço da panícula não foi detectada interação significativa entre os fatores doses e épocas, mas foram isoladamente significativos. Estudando-se as doses (Figura 2), constata-se que a severidade da doença aumentou linearmente com o incremento das doses de $\mathrm{N}$, corroborando os resultados de Santos et al. (1986) de que doses elevadas de $\mathrm{N}$ aumentam a severidade da brusone.

As notas médias de severidade da brusone no pescoço da panícula em função das diferentes épocas de aplicação de $\mathrm{N}$ no cultivo do arroz de terras altas (Tabela 1) indicam que a menor severidade da doença ocorreu quando o adubo foi todo aplicado no plantio, embora não tenha diferido estatísticamente dos resultados da aplicação de 1/ 2 no plantio e 1/2 na DPF. Esses resultados indicam que o

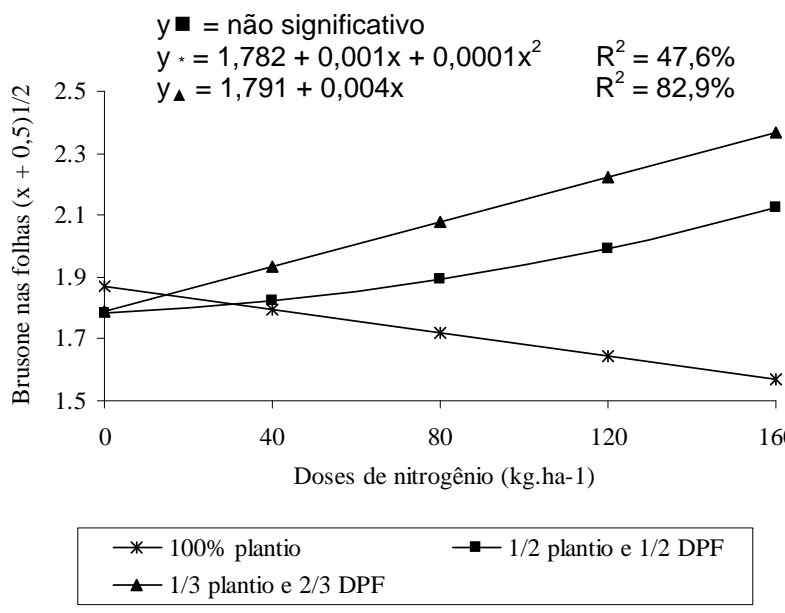

FIGURA 1 - Efeito de doses de $\mathrm{N}$ combinadas com três épocas de aplicação sobre a severidade de brusone nas folhas em arroz de terras altas. EPAMIG, Lavras MG, 2004.

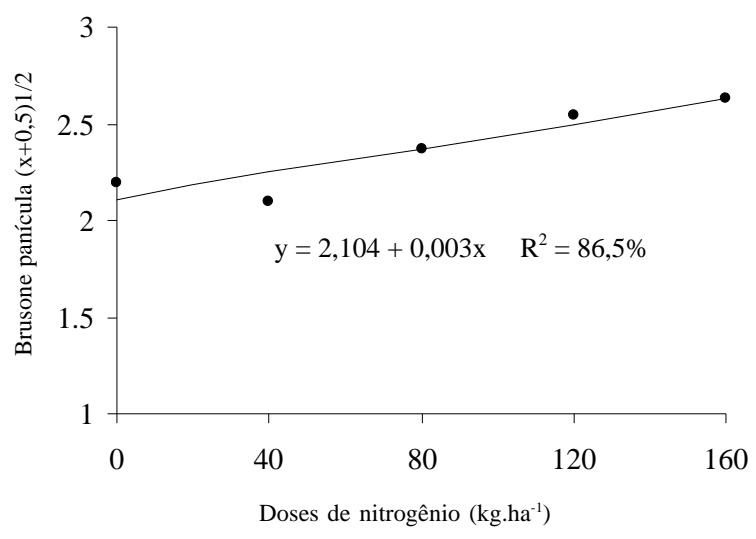

FIGURA 2 - Efeito de doses de $\mathrm{N}$ para a severidade de brusone do pescoço da panícula em arroz de terras altas. EPAMIG, Lavras, MG, 2004. 
parcelamento da adubação nitrogenada favoreceu o desenvolvimento do fungo na região do pescoço da panícula. Este fato ocorreu uma vez que, quanto mais tardiamente for aplicado o $\mathrm{N}$ de cobertura maior será seu aproveitamento na forma de nitrato, e maior utilização do $\mathrm{N}$ favorece a doença.

Os resultados dos testes de sanidade nas sementes colhidas em função de doses e épocas de aplicação de $\mathrm{N}$ não foram significativos para os fungos Phoma $s p$, que apresentou incidência média de 50,12\%, e para Gerlachia oryzae, com média de 1,30\%. Portanto, o índice de Phoma $s p$ nas sementes foi bastante elevado, sugerindo que este é um dos principais fungos causadores da mancha de grãos nas sementes de arroz produzidas na região.

TABELA 1 - Severidade de brusone no pescoço da panícula atribuídas a plantas submetidas a diferentes épocas de aplicação de nitrogênio no cultivo do arroz de terras altas. EPAMIG, Lavras, MG, 2004.

\begin{tabular}{lc}
\hline Épocas de aplicação de $\mathbf{N}$ & Notas de $\mathbf{B P}(\sqrt{\mathbf{x}+\mathbf{0 , 5})}$ \\
\hline Todo no plantio & $4,47 \mathrm{a}$ \\
$1 / 2$ plantio e $1 / 2$ DPF & $5,31 \mathrm{ab}$ \\
$1 / 3$ plantio e 2/3 DPF & $5,55 \mathrm{~b}$
\end{tabular}

Médias seguidas das mesmas letras não diferem entre si pelo teste de Tukey a 5\% de probabilidade.

A avaliação da incidência de Pyricularia grisea nas sementes encontra-se na Figura 3. Observa-se que o percentual de ocorrência do patógeno foi elevado e aumentou em função do incremento da dose de $\mathrm{N}$, indicando o efeito desse nutriente no aumento do fungo na semente. Assim, pode-se inferir que doses altas de $\mathrm{N}$ nos campos de produção de sementes favorecem a ocorrência do fungo $P$. grisea nas sementes, aumentando os riscos de condenação.

Para o fungo Drechslera oryzae, houve interação significativa entre os fatores doses e época de aplicação de N (Figura 4). Verifica-se que as doses de 40 e $80 \mathrm{~kg}$. ha ${ }^{-1}$ de N aplicada $100 \%$ no plantio produziram sementes com menor percentual de $D$. oryzae. Por esse resultado nota-se que para a aplicação do $\mathrm{N}$ todo no plantio, tanto a ausência quanto o excesso de $\mathrm{N}$ favoreceram a ocorrência de $D$. oryzae nas sementes e, ainda, que doses moderadas, na faixa de 40 a $80 \mathrm{~kg} \cdot$ há $^{-1}$ de $\mathrm{N}$ atenuam a ocorrência do referido patógeno. No caso do parcelamento do $\mathrm{N}$ em duas épocas, as diferentes doses de $\mathrm{N}$ não interferiram na ocorrência de D. oryzae nas sementes.

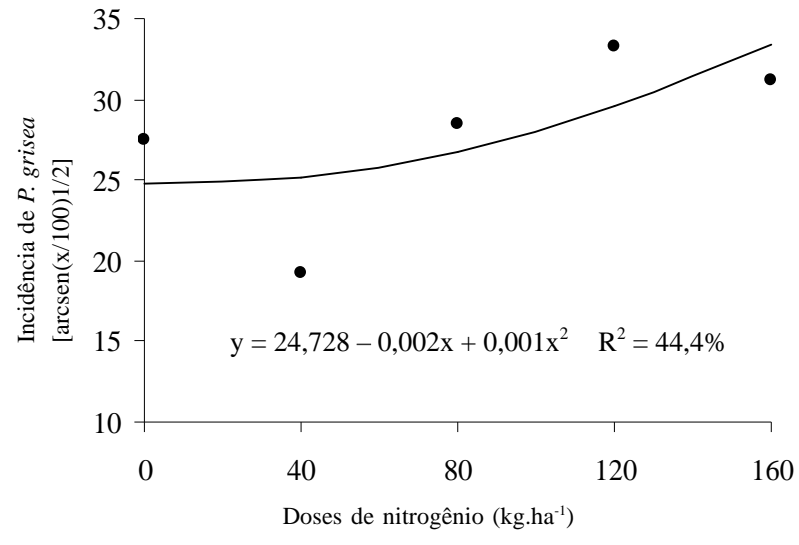

FIGURA 3 - Percentual médio de incidência de Pyricularia grisea em sementes de arroz de terras altas em função de diferentes doses de nitrogênio. EPAMIG, Lavras, MG, 2004.

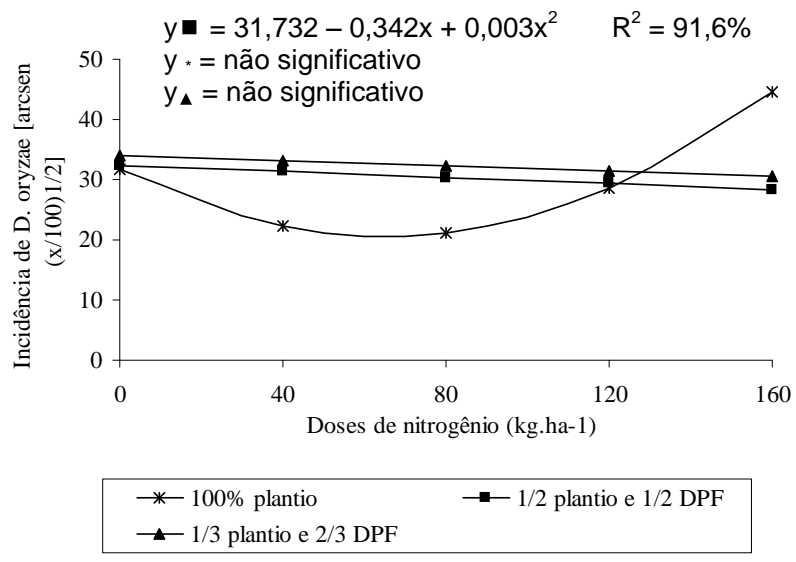

FIGURA 4-Percentual médio de incidência de Drechslera oryzae em sementes de arroz de terras altas em função de diferentes doses de nitrogênio. EPAMIG, Lavras, MG, 2004.

Com relação à produtividade de grãos os fatores doses e época de aplicação de $\mathrm{N}$ foram significativos, indicando a influência de ambos sobre essa característica. Pela figura 5 verifica-se que à medida que aumentou as doses de $\mathrm{N}$ houve também aumento da produtividade. Este resultado é semelhante ao encontrado para brusone na panícula onde a severidade da doença aumenta com o incremento das doses de N. Apesar de doses crescentes de $\mathrm{N}$ aumentarem tanto a incidência de brusone na panícula, quanto a produtividade de grãos isso não pode ser considerado uma incoerência, pois dependendo do estádio de desenvolvimento da panícula em que o fungo ataca, o

Ciênc. agrotec., Lavras, v. 31, n. 1, p. 47-52, jan./fev., 2007 
prejuízo ao enchimento de grãos é pequeno. A resposta da produtividade de grãos do arroz a doses elevadas de $\mathrm{N}$ já foi bastante estudada e é positivamente correlacionada. Portanto, nesse estudo, tanto a produção de grãos quanto a incidência de brusone na panícula foram favorecidas por doses crescentes de $\mathrm{N}$.

Os resultados de média de produtividade de grãos, em função de diferentes épocas de aplicação de $\mathrm{N}$, encontram-se na Tabela 2. Observa-se que a menor produtividade ocorreu quando todo $\mathrm{N}$ foi aplicado no plantio. Embora a severidade da brusone na panícula (Tabela1) tenha sido menor, quando o $\mathrm{N}$ foi todo aplicado no plantio a produtividade também foi inferior, indicando que mesmo aumentando a severidade da brusone na panícula, o parcelamento do $\mathrm{N}$ foi favorável ao aumento da produtividade. Como já discutido, no sistema de cultivo do arroz em terras altas quanto mais tardiamente e próximo

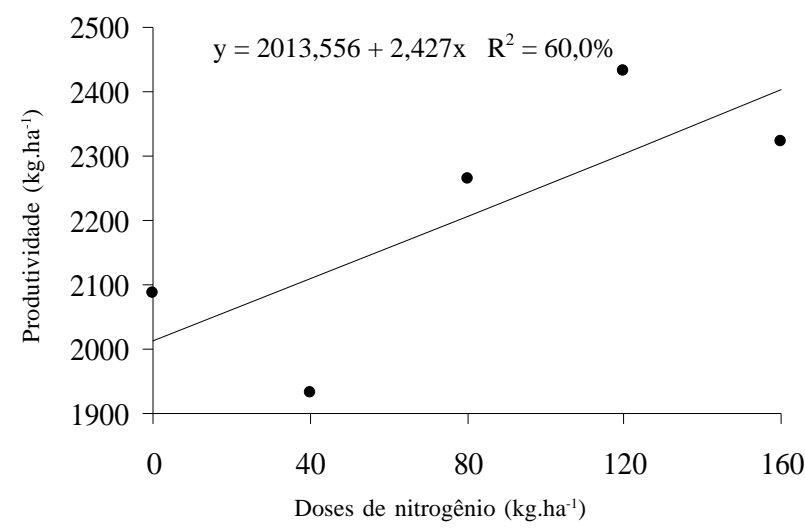

FIGURA 5 - Média de produtividade de arroz de terras altas em função de diferentes doses de nitrogênio. EPAMIG, Lavras, MG, 2004.

TABELA 2-Média de produtividade de sementes (kg.ha-1) para diferentes épocas de aplicação do Nitrogênio no cultivo do arroz de terras altas.

\begin{tabular}{lc}
\hline Épocas de aplicação de $\mathbf{N}$ & Produtividade \\
\hline Todo no plantio & $1946 \mathrm{a}$ \\
$1 / 2$ plantio e $1 / 2 \mathrm{DPF}$ & $2230 \mathrm{ab}$ \\
$1 / 3$ plantio e 2/3 DPF & $2446 \mathrm{~b}$
\end{tabular}

Médias seguidas das mesmas letras não diferem entre si pelo teste de Tukey a 5\% de probabilidade. EPAMIG, Lavras, MG, 2004. a diferenciação do primórdio floral for aplicado o N, maior será seu aproveitamento pela planta, pois a partir dessa idade a planta produz mais eficientemente a enzima redutase do nitrato e maior será a utilização do $\mathrm{N}$ nítrico, que é predominante nesse sistema de cultivo.

\section{CONCLUSÕES}

A aplicação de todo $\mathrm{N}$ no plantio não promoveu condições favoráveis para uma maior severidade da brusone da folha.

Quanto maior foi a dose de $\mathrm{N}$ aplicado na diferenciação do primórdio floral, maior a severidade da brusone do pescoço da panícula.

Doses crescentes de $\mathrm{N}$ favorecem a incidência de $P$. grisea em sementes e também a produtividade no arroz de terras altas.

Para o arroz de terras altas, em caso de parcelamento, concentrando-se a maior quantidade de $\mathrm{N}$ próximo a diferenciação do primordio floral, onde o aproveitamento desse elemento é mais eficiente, favorecerá uma maior produtividade da cultura, mas também maior ocorrência de brusone do pescoço da panícula.

\section{REFERÊNCIAS BIBLIOGRÁFICAS}

EMPRESA BRASILEIRA DE PESQUISA AGROPECUÁRIA. Manual de métodos de pesquisa em arroz. Brasília, DF, 1977. 106 p.

FERNANDES, J. M. C. As doenças das plantas e o sistema de plantio direto. Revisão Anual de Patologia de Plantas, Passo Fundo, v. 5, p. 317-352, 1997.

GUIMARÃES, C. M.; YOKOYAMA, L. P. O arroz em plantio direto. In: BRESEGHELLOF, F.; STONE, F. L. (Eds.). Tecnologia para o arroz de terras altas. Santo Antônio de Goiás: Embrapa Arroz e Feijão, 1998. p. 25-30.

HUBER, D. M. The role of mineral nutrition in defense. In: HORSFALL, J. G.; COWLIN, E. B. (Eds.). Plant disease: an advanced treatise. New York: Academic, 1980. v. 5, p. 381406.

KRUGNER, T. L. Ação do ambiente sobre as doenças de plantas. Agronômica Ceres, Viçosa, v. 1, p. 215-226, 1978.

NEERGAARD, P. Seed pathology. London: MacMilan, 1977. $1187 \mathrm{p}$. 
OU, S. H. Rice disease. 3. ed. Kew: Mycological Institute, 1987. $368 \mathrm{p}$.

PHILLIPS, S. H. No tillage-past, present and future. In: SIMPÓSIO INTERNACIONAL SOBRE PLANTIO DIRETO EM SISTEMAS SUSTENTÁVEIS, 1993. Proceedings... [S.1.]: ABC, 1993. p. 9-12.

REIS, M. de S.; SOARES, A. A.; GUIMARÃES, C. M. Plantio direto em arroz. Informe Agropecuário, Belo Horizonte, v. 25 , n. 222 , p. 49-57, 2004.

SANTOS, A. B. dos; PRABHU, A. S.; AQUINO, A. R. L. de; CARVALHO, J. R. P. de. Épocas, modos de aplicação e níveis de nitrogênio sobre brusone e produção de arroz de sequeiro. Pesquisa Agropecuária Brasileira, Brasília, v. 21, n. 7, p. 697-707, 1986.

SILVA, G. B. da; PRABHU, A. S. Progresso da brusone nas folhas no plantio direto e convencional de arroz de terras altas. Fitopatologia brasileira, Brasília, v. 29, p. 316-318, 2004.

WEBSTER, R. K.; GUNELL, P. S. Compendium of rice disease. Minnesota: APS, 1992. 62 p.

ZAMBOLIN, L.; VENTURA, J. A. Resistência a doenças induzida pela nutrição mineral de plantas. Revisão Anual de Patologia de Plantas, Passo Fundo, v. 1, p. 275-318, 1993. 